\title{
Innovative Talent Training Mode Based on Academic Competition and Engineering Training
}

\author{
Shigang Wang ${ }^{1, a^{*}}$, Zhengqiang Chen ${ }^{1, b}$ and Fengyi Liao ${ }^{1, c}$ \\ ${ }^{1}$ School of Electrical and Information Engineering, Guangxi University of Science and Technology, \\ 545006 Liuzhou, China \\ ahljwangsg@163.com, b88935113@qq.com, c1272037115@qq.com
}

*The corresponding author

Keywords: Innovative talents; Training mode; Academic competition; Engineering training

\begin{abstract}
To cultivate high-quality innovative talents with innovative consciousness and entrepreneurial ability, meet the social and economic development and progress of science and technology needs, so as to improve the international competitiveness in order to adapt to the changing international environment and future challenges in the world. Relying on academic competition, to carry out innovation and entrepreneurship education, deepen the reform of professional courses, build academic competition platform. To establish a new teaching system of engineering training and scientific and technological innovation, and to carry out the project oriented teaching mode based on the gradual hierarchical engineering training. It provides a training mode for cultivating innovative talents with innovative and entrepreneurial consciousness.
\end{abstract}

\section{Introduction}

To deepen reform and improve quality, we must insist on cultivating innovative talents. Innovation is the soul of a nation and the inexhaustible motive force for the prosperity of a country [1]. At present, it is the requirement of the times to improve the innovative spirit and creative ability of students. At present, the fundamental problem of higher education is the quality of personnel training, the core of which is the cultivation of students' creativity, innovation and entrepreneurial consciousness, concept and ability [2]. This is fully reflected on the social and economic objective of higher education, is the internal demand and regularity of social economic development on the teaching quality of higher education, the form is a combination of higher education and science and technology and the economy, culture and society, promote scientific and technological innovation and research in the humanities and social sciences, to accelerate the transformation scientific and technological achievements into practical productive forces, promote advanced culture progress continuously, creating talents of hundreds of millions of high-quality workers, tens of millions of dollars and a large number of innovative talents [3-5]. The university as the main force of higher education, talents "export commodity production" or the last "process", the cultivation and training of innovation ability is the core element of "market quality, brand", is the focus of the society, is to deepen the reform of colleges and universities, improve the educational quality of the hot and difficult [6]. Therefore, it is of great theoretical and practical significance to explore the mode of innovation and entrepreneurship education in universities, especially in local universities.

Cultivating innovative talents for the society is one of the main tasks of universities. Carrying out innovation and entrepreneurship education, to cultivate a large number of innovative, entrepreneurial spirits and ability of high-quality innovative talents, meet the social and economic development and progress of science and technology needs, so as to improve the international competitiveness of a country in order to adapt to the changing international environment and the future of world challenge [7]. Carrying out innovation and entrepreneurship education, not only shows the characteristic of the education thought of keeping pace with the times, also means the developing pattern of the continuous changes to adapt to the education goal time for ideological education, educational methods and talents, to cultivate and improve students' innovative spirit and entrepreneurial ability and the ability to adapt, to 
solve the employment problem brought to the popularization of higher education and realize the smooth development of higher education.

With the development of social economy, the ministry of education has issued a series of policies and measures to strengthen the teaching work and improve the teaching quality. Clearly put forward the requirements for the cultivation of innovative talents in universities, put into the "practical innovation" reform mode of teaching and training is the important content of strengthening the construction work of engineering training and technology competition, and carry out the engineering training and academic competition activities, stimulate students' interest and potential, to cultivate students' sense of teamwork and innovation spirit.

\section{Based on Academic Competition, to Create a Diversified Innovation and Entrepreneurship Education Platform}

(1) Build a platform for college students' academic competition. The creation of innovative practice classes with different characteristics, the academic competition as an effective carrier to carry out practical teaching. Set up special funds to encourage students to participate in academic competition incentive policy. To develop the evaluation system of students' scientific research ability. On the basis of this platform, students are encouraged to rely on academic competition to complete the practical teaching links, such as comprehensive practice, innovation credit and so on. For students to carry out extracurricular science and technology activities to provide a reliable platform and resources.

(2) To carry out innovation and entrepreneurship education on the basis of academic competition. In order to provide the necessary conditions and stage for college students to carry out innovation and entrepreneurship education, and to cultivate the creative ability of college students. By relying on scientific and technological competition, cultivating students' scientific spirit and creative methods; establishing innovative education evaluation system, change the examination method simply closed; construction of a new teaching mode with students as the center, with the basis of students' activity, teaching activities based on autonomic activities, students active exploration, conducive to the formation of students' subject consciousness, creation consciousness and creation ability of healthy development of the teaching environment and teaching system.

(3) Advocate the academic competition of college students; deepen the construction of specialized courses. Academic competitions is a comprehensive application and extension of knowledge in class, so in the course of teaching system, should pay attention to basic training, comprehensive training and professional training and other construction practices, and the creation of creation and innovation thinking training and competition related elective courses, so that students can improve their scientific research ability and practical ability in the professional teaching in class. The traditional classroom teaching professional foundation class as the main body, the teaching methods and means of various forms, rich, targeted to the introduction of network teaching, multimedia teaching, simulation technology and other forms of training for professional students' innovative consciousness and ability, expand the professional basic course teaching of the depth and breadth, adapt to the teaching reform and training the talent needs.

Fig. 1 is the academic competition management mode. The formation of extracurricular science and technology competition organization (Group) is a "learning community" by teachers and students (the ecological system composed of science and technology activities, and other means of ecological factors perplexing). This paper is based on the viewpoint of ecology science and technology as the guide, with ecological research requirements of harmonious balanced treatment of scientific research of the interaction between these factors and the way of activity, means of implementation, activities and other forms of organization, academic activities including operation mechanism, establish ecological: Extracurricular academic competition content structure harmonious balance, extracurricular academic competition organizational structure the harmonious balance between guided and guided the harmonious balance, extracurricular academic competition environment harmonious balance, extracurricular academic competition of vertical and horizontal structure and within a harmonious balance of science and technology contest theme content related knowledge structure and cognitive 
structure balance, establish the harmonious balance on the basis of extracurricular activities in science and technology operation based on the mechanism.

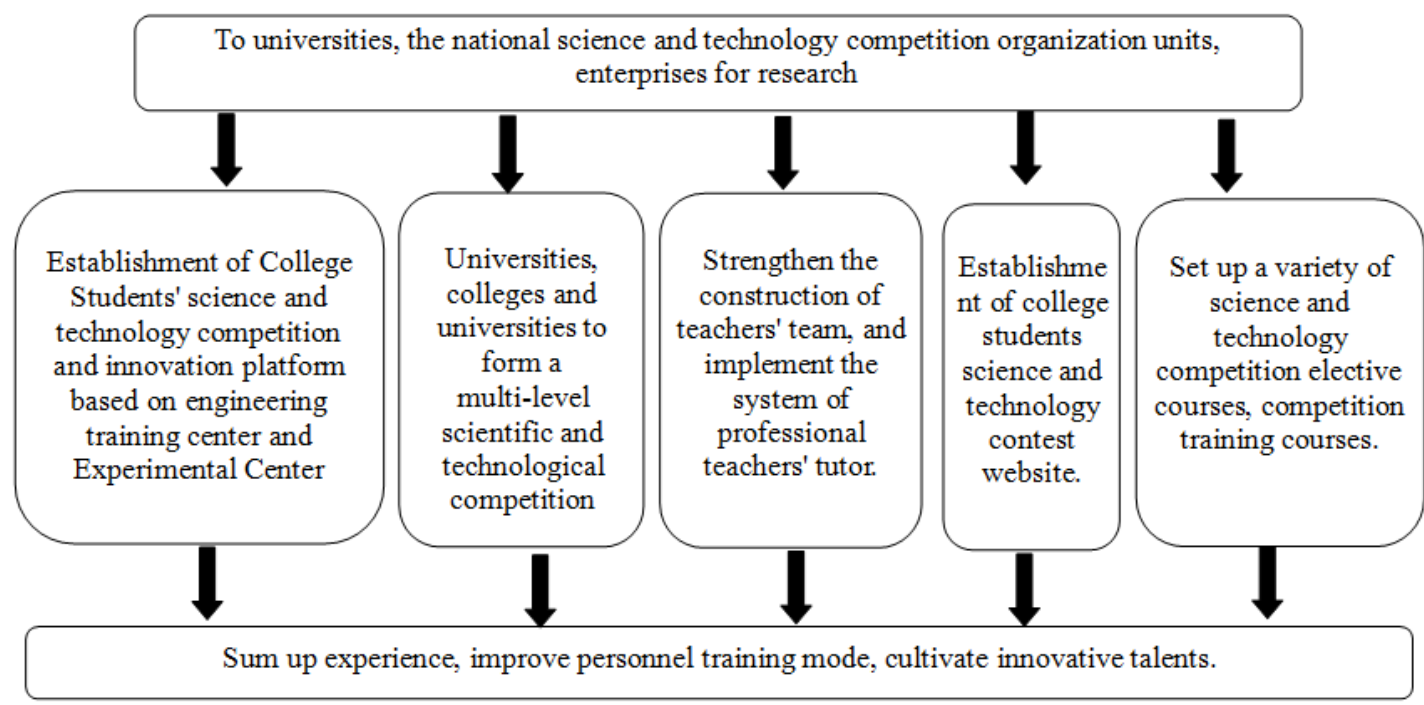

Figure 1. Science and technology competition management mode

"Extracurricular academic competition organization mode of three-dimensional" refers to the technical invention and product innovation, technological innovation, public opinion research, social development and social practice as the goal, to mentor in the research project, students choose project enterprise development project commissioned, the relevant government department commissioned and find the target project as the main form and the cross, cross department, interdisciplinary and professional teachers and students jointly organized a multi-level, multi form and multi channels to carry out the diversification process of technological innovation, the academic activities has important practical significance to breakthrough. Practice shows that the multi-level and diversified and interactive features of "three-dimensional" extracurricular academic competition organization model is the realization of extracurricular academic competitions of scientific development and improve the pertinence and effectiveness of the inevitable choice.

\section{Constructing a New Engineering Training system, Strengthening the Cultivation of Students' Scientific and Technological Innovation Ability}

(1) The basic train of thought and implementation principle of constructing the new engineering training system [8]. Engineering, circulation, circulation and taught to do learning cycle "three layer circulation" teaching model must be strong training resources, cultivate students' occupation ability and learning ability is only through a large number of effective internal and external training activities can be achieved, and the theory and practice of a body, the quality of teachers and technicians, quality development the construction of training base school enterprise integration, integration, evaluation and development of skills identification is a new type of engineering training system the basic train of thought. To train the new engineering training system for implementation of the principle of the spirit of "time and space have enough room on the premises, mechanism of full freedom" principle, to undergraduate research assistant "long-term culture" and "short-term interest" in the form of implementation of the training process. The practical system has strong pertinence, diversity and multi-level.

(2) To establish a new teaching system of engineering training and technology innovation. Study on the establishment of engineering training and new technology collaborative innovation system, the characteristics of the system that reflects the hierarchical, modular, extension, extracurricular lessons outside to class feedback, for all students, through the four years of undergraduate teaching, cultivating innovative ability. A simple to complex, from perceptual to rational, comprehensive, from basic to the extra-curricular, from low grade to include basic training, comprehensive training, expand the layer and 
layer training innovative practice step by step the new teaching content system of high grade. To realize the "science and technology oriented, multi selection of independent innovation experimental environment, and means of multi-dimensional assessment method and multi platform open management" is the basic characteristic of the practice teaching mode diversification, guide the students from the past "learning and test" to "learning, thinking, research, practice and innovation" change.

Study in accordance with the different levels and stages of training, training in basic training to complete the project, on the one hand by taking part in the skills competition and occupation training, to enhance the practical ability of students to obtain proficiency in a particular line, to stimulate interest in learning; on the other hand, through the course of the teaching plan and second classroom discipline activities of the organization and arrangement, in order to open the appointment of innovative practice base, driven by interest to develop students' innovative ability, to cultivate students' comprehensive ability. The establishment of a student oriented, desalination professional, throughout the university learning career with the knowledge of cross training, engineering training methods and means of teaching.

Training mode of scientific research assistant. According to the differences in grade, professional background, recruitment of college students' scientific research base to develop an assistant, the fourth grade students' innovation ability training system for freshman, sophomore, the implementation of the "science popularization project", mainly to carry out rich and colorful extracurricular activities of science and technology, to carry out creative and innovative education. To develop the basic scientific literacy and cultural spirit; for the implementation of the "Junior Project Engineering Research (or undergraduate innovative experiment program)", the junior into all kinds of scientific research practice, the research of the participating teachers. Organize students to participate in the extracurricular work and the "Challenge Cup" competition, and actively encourage students to publish scientific papers, for creative project support; for senior and graduate students, the implementation of the "technology innovation project", advocating the concept of entrepreneurship to employment change, improve entrepreneurial mechanism conducive to the development of students.

(3) To establish the project based teaching model. The project training teaching mode which based on a project to complete the training task, according to the interest and ability of independent choice of training project, in the process of training and guidance of teachers, students often discuss. Modern engineering training is in manufacturing engineering, as the background, fully embodies the modern design technology and modern manufacturing technology, modern control technology and modern management technology development direction, for students, to provide a modern, comprehensive, experience of product design, manufacturing, management control integration industrial simulation environment, the students acquire procedural knowledge in typical field or device, to build a new type of engineering training teaching mode to meet the engineering training under the new situation required under this premise [9]. The engineering training center students according to the selected item, taking innovation as the charm, practice as a means to guide the students to complete the project, project specific tasks for the training of the main line, to stimulate students' interest in learning in the training process, expand the engineering practice ability, change passive learning into active learning, awareness and ability of students' autonomous learning the students find and solve problems in consciousness and ability, so that the engineering practice ability and innovation ability to effectively train.

(4) Progressive stratified engineering training mode. According to the laws of the students' cognitive process, setting of training program is from simple to complex, from perceptual to rational, from foundation to comprehensive, from inside to outside, from junior to senior. It is multi-level, comprehensive. The content of the project which is throughout the whole process of teaching of undergraduate course highlights the cultivation of innovation ability [10].

The training program engineering training center set is divided into four levels, as shown in Fig. 2; each level has different content and different credit training programs for students to choose. 


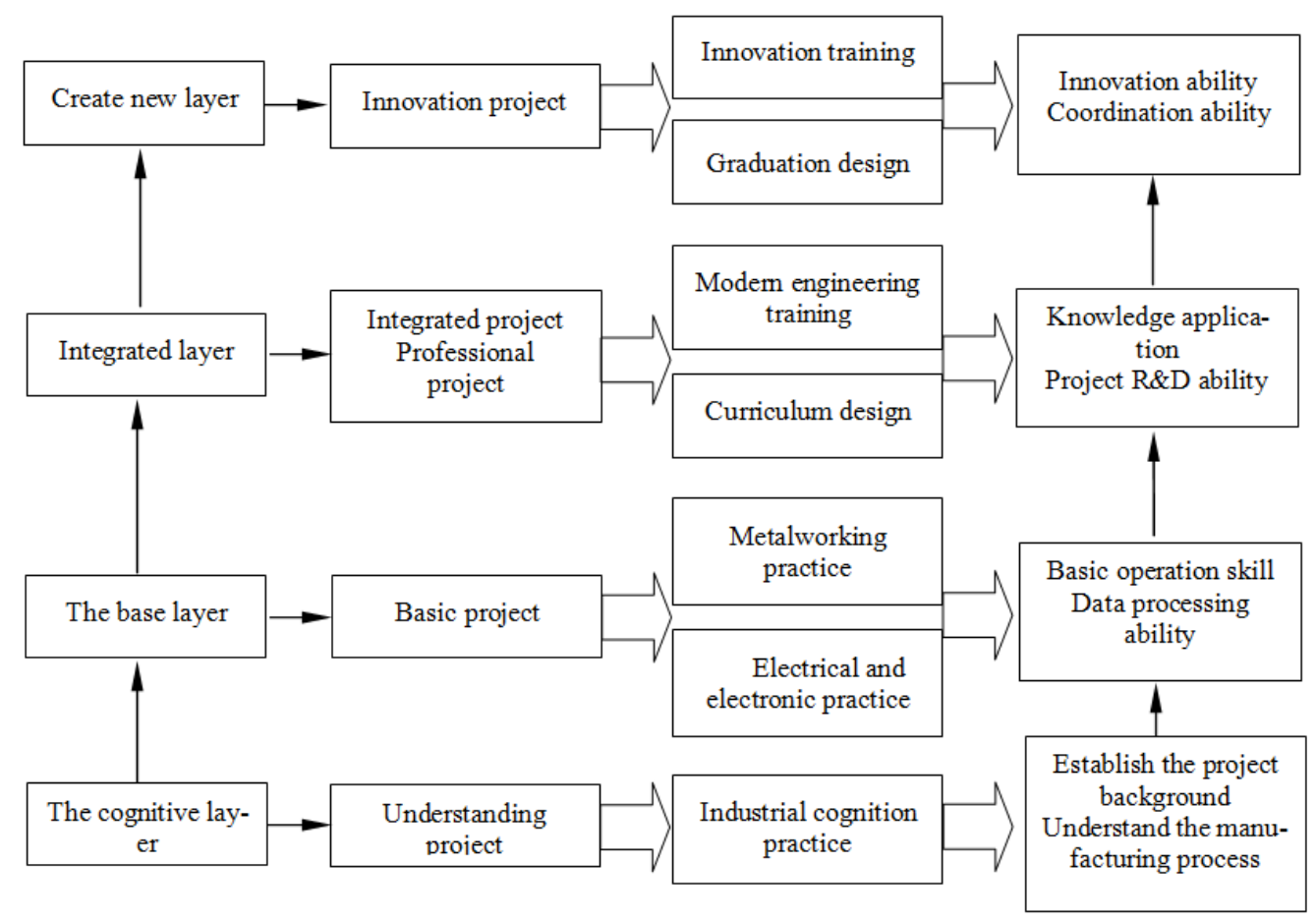

Figure 2. Progressive stratified engineering training mode

\section{Summary}

To improve the students' quality of science and technology and engineering ability is of great significance for the cultivation of innovative talents, academic competition is an important means to improve students' quality of science and technology, engineering training is a necessary step to strengthen students' practical ability. To carry out the research on the training mode of innovative talents and academic competitions based on engineering training, can promote college students' scientific and technological practice, promote reform of teaching, training students' practical ability, enhance students' competitive consciousness, cultivate students' team spirit as well as in the design and development of innovation consciousness, advocate the theory and practice of the study opens an effective way for the cultivation of innovative talents. Through research and exploration, to build a comprehensive scientific management mechanism, standardized and systematic academic competitions, training platform for the establishment of academic competition the innovative ability of college students, and carry out the creation, innovation and entrepreneurship education, based on all kinds of students' scientific and technological competitions and training, all-round reform in terms of innovation and entrepreneurship education mode education, curriculum system, teaching methods and means of training, can understand the professional knowledge and skills, but also has high management ability, innovative spirit and entrepreneurial quality and practical ability, innovative talents with advanced application of the local characteristics.

\section{Acknowledgment}

This work was supported by the Degree and Postgraduate Education Teaching Reform Project in Qiqihar University (Grant No. JGXM_QUG_Z2015001) and Education Teaching Reform Project in Guangxi University of Science and Technology (Grant No. 2016-01).

\section{References}

[1] Liu Fengfu, Implementation of innovative education to cultivate the innovative talents, Technological Pioneers, 2 (2012), pp. 214-215. 
[2] Freeman C, Soete L, The Industrial Innovation, Cambridge, MA: MIT Pres, 1997.

[3] Wang Haocheng, Feng Zhiyou, Wang Wentao, Construction of laboratory of thinking innovation based on cultivating innovative spirit and practical ability, Experimental Technology and Management, 30, 7 (2013), pp. 198-200.

[4] Ma Lingling, An Empirical Study on Developing Students' Autonomy Learning Ability through Project-Based Learning, Journal of Shanxi Radio \& Tv University, 3 (2010), pp. 54-55.

[5] Bingbing Yan, Tianlu Wei, Dejun Li, Analysis and countermeasures on the current situation of college enrollment education mode in local colleges and universities, Education and Vocation, 7 (2016), 25-27.

[6] Li Hongwei \& Zhang Zhiyuan, Study on training model for mechanical engineer oriented practice application. Mechanical Management and Development, 25 (2010), pp. 149-150

[7] Zhu Congrong, Fostering innovative talents of mechanical engineering major in local colleges and universities, Research and Exploration in Laboratory, 28 (2009), pp. 116-118.

[8] Yu Zhaoqin, Wu Fugen, Guo Zhongning, Project-driven based modern engineering training methods, Research and Exploration in Laboratory, 31 (2012), pp. 131-133.

[9] Li Zehui, Application of project-driven mode in the engineering knowledge course, Experiment Science and Technology, 9 (2011), pp. 133-134.

[10] Sha shujing, Based on project driven mechanical professional teaching model to explore and practice, Journal of Changchun University of Science and Technology, 7 (2012), pp. 207-208. 